Original article

\title{
Overexpression of estrogen and progesterone receptors as indicator of endometrial receptivity disorder in women with early miscarriage
}

\author{
Sergey S. Aganezov ${ }^{1}$, Vera N. Ellinidi ${ }^{2}$, Kristina Yu. Ponomarenko ${ }^{1}$, Anastasiya V. Morotskaya ${ }^{1}$, \\ Natalia V. Aganezova ${ }^{1}$ \\ ${ }^{1}$ North-Western State Medical University n.a. I.I. Mechnikov, St. Petersburg, Russia \\ ${ }^{2}$ Federal Center of Emergency and Radiation Medicine n.a. A.M. Nikiforov, St. Petersburg, Russia
}

Received 19 September 2018, Revised 24 February 2020, Accepted 22 April 2020

(C) 2018, Aganezov S.S., Ellinidi V.N., Ponomarenko K.Yu., Morotskaya A.V., Aganezova N.V.

(C) 2018, Russian Open Medical Journal

Abstract: Background - The endometrial factor is important in miscarriage (MC) pathogenesis.

Objective. To perform a morphofunctional evaluation of endometrium in the patients with uncertain MC cause in anamnesis.

Material and methods - We examined 48 women $23-40$ yo $[30(27,35)]$ : the main group consisted of 33 patients with early MC in their medical history, while the control group included 15 healthy fertile women. All women had an ovulatory menstrual cycle, normal levels of gonadotropic and thyroid hormones, prolactin, and androgens. Ultrasound and hormonal examinations, along with morphological investigation of endometrial biopsies were performed. Data presented as median with lower and upper quartiles $-\mathrm{Me}(\mathrm{LQ}, \mathrm{UQ}$ ).

Results - In 64\% ( $n=21$ ) of women in the main group, we detected inferior secretory phase of their endometrial cycle, focal fibrosis of endometrial stroma; synchronous overexpression of estrogen (ER) and progesterone (PR) receptors in endometrial glands and stroma. ER in the glands was $240(160,280)$ vs. $130(80,210)$ in the stroma, while PR values were $270(210,290)$ in the glands vs. $270(240,280)$ in the stroma: differences from the control group were significant $(p<0.01)$. Remaining women in the main group $(36 \%, n=12)$ and all women in the control group had full secretory transformation of the endometrium and normal expression of ER and PR. The levels of estradiol and PR in the blood of women with early MC in anamnesis, with different variants of ER and PR expression in the endometrium, did not differ significantly from the control group and corresponded to the reference values.

Conclusion - Nearly two-thirds of women with early miscarriage in anamnesis exhibited overexpression of ER and PR in the endometrium, which may be one of the indicators of its decreased receptivity status.

Keywords: endometrial receptivity, miscarriage, progesterone and estrogen receptors.

Cite as Aganezov SS, Ellinidi VN, Ponomarenko KYu, Morotskaya AV, Aganezova NV. Overexpression of estrogen and progesterone receptors as indicator of endometrial receptivity disorder in women with early miscarriage. Russian Open Medical Journal 2020; 9: e0211.

Correspondence to Natalia V. Aganezova. Address: Department of Obstetrics and Gynecology, North-Western State Medical University n.a. I.I. Mechnikov, Saint Petersburg, Russia. E-mail: aganezova@mail.ru.

\section{Introduction}

According to recommendations of the European Society of Human Reproduction and Embryology (ESHRE), 2017, experts specify recurrent miscarriage (MC) as two or more clinical pregnancy failures in anamnesis [1]. In a broader contemporary contemplation of the problem, it is necessary to study the causes and pathogenesis of such repeated pregnancy failures, as recurrent $M C$ or a premature birth, along with recurrent implantation failures (RIF), i.e. lack of pregnancy when good quality embryos are transferred to the uterus [2,3].

The endometrial factor is crucial for pathogenesis of recurrent MC [4]. Endometrial receptivity, first proposed in 1976 by $A$. Psychoyos, refers to a combination of structural and functional endometrial traits creating conditions for successful blastocyst implantation [5]. Many contemporary studies were devoted to investigating endometrial receptivity in women with reproductive dysfunctions. Their authors described morphological characteristics of the endometrium in women with a history of reproductive ailments in the presence of uterine fibroids, endometriosis, inflammatory disorders of the genitals, nutritional endocrine disorders, and combined pathology. Among available publications, we did not find any describing the traits of hormone-receptor interaction in the endometrium of women with reproductive dysfunctions (in particular, $\mathrm{MC}$ ) in anamnesis of uncertain origin, in the absence of probable causes of pregnancy failures.

Women with recurrent $M C$ in anamnesis are prescribed progestogens during their pregnancies [1]. N. Pluchino et al. (2015) recommended using gestagens to correct the luteal phase in women with $\mathrm{MC}$ as early as at the pregravid stage [6]. It is well known that progesterone $(P)$ effects play a leading role in preparing the endometrium for embryo implantation and providing a favorable environment for developing the ovum in conditions of immunological relationships between the mother's body and the ovum, half alien in its antigenic composition. The adequacy of $P$ effect on the uterine mucous membrane is 
determined by the number and quality of nuclear receptors for steroid hormones, as well as by the effectiveness of $P$ molecules' interaction with such receptors [7]. We are well aware that insufficient PR effects are among the causes of structural and functional endometrium traits' disorders during spontaneous abortions [8]. At the same time, the negative influence of the excessive $P$ effect on embryo implantation and endometrial decidualization has been shown as well [9]. Clinical data on menstruation regularity, the "ovulatory" $P$ level in blood, and ultrasound characteristics of two-phase menstrual cycle do not reflect the extent of hormone-receptor interactions in the endometrium. It remains unclear who, in fact, needs an additional progestogen therapeutic effect in potential conception cycles.

The vast majority of scientific publications presented the results based on using simultaneously two methods of examining patients with reproductive dysfunctions in the anamnesis: hormonal and ultrasound, hormonal and histological, or ultrasound and histological. None of those combinations provided sufficient information for analyzing quality of the entire menstrual cycle, including the endometrial level.

A comprehensive investigation of estradiol $\left(E_{2}\right)$ and $P$ levels in the blood, ultrasound monitoring data on "ovarian cycle" and endometrium, and the results of morphological (histological and immunohistochemical) studies of the endometrium were described by few authors $[10,11,12]$.

Overall, there is scarce information in the specialized literature about the proportion of women with uncertain MC history who underwent comprehensive examinations and, in the presence of a full ovulatory menstrual cycle, had inadequate hormone-receptor interactions in the endometrium.

The objective of our study was conducting a morphofunctional evaluation of the endometrium in patients with early $M C$ of uncertain genesis.

\section{Material and Methods \\ Subjects}

Our study included 48 women of reproductive age (23-40 yo). The study was performed using clinical facilities of the Department of Obstetrics and Gynecology, I.I. Mechnikov North-Western State Medical University, Ministry of Healthcare of the Russian Federation, Federal State Budgetary Institution "D.O. Ott Research Institute of Obstetrics, Gynecology and Reproductive Medicine", and A.M. Nikiforov Federal Center of Emergency and Radiation Medicine, EMERCOM of Russia. The study was approved by the Ethics Committee of the I.I. Mechnikov North-Western State Medical University, Russian Federation Ministry of Healthcare.

The main study group consisted of 33 female patients 23 to 40 years old (Table 1 ) with early $\mathrm{MC}$ of uncertain origin. The following categories of women were excluded from the study: with severe somatic disorders; obesity; any oncological processes; thrombophilia; uterus abnormalities; clinically significant uterine fibroid (submucosal fibroid; subserosal-intramural fibroid exceeding $3 \mathrm{~cm}$ ); infectious inflammatory process of the urogenital tract at the moment of planned manipulation (endometrial aspiration biopsies); taking hormonal medications (sex steroids) for three months before being admittance to the study.

The control group consisted of 15 somatically healthy women 23-40 yo (Table 1), without a history of reproductive and menstrual dysfunctions, examined in connection with a diagnosis of "infertile marriage" due to male infertility, as well as women volunteers and patients from the archival databases of the Anatomical Pathology Department at A.M. Nikiforov Federal Center of Emergency and Radiation Medicine, EMERCOM of Russia.

All women signed voluntary informed consent for inclusion in the study.

\section{Methods}

An analysis of 120 menstrual cycles (at least two in each woman) was carried out: including the following components: ultrasound examination (folliculogenesis monitoring, visualization of the corpus luteum in the ovary), and $P$ level investigation in peripheral blood in the middle of the luteal phase of the menstrual period.

On all participants, on the day 6-8 after the ovulation - on average, on the day 20-22 of the menstrual cycle (d.m.c.), - an endometrial aspiration biopsy was performed at the outpatient department of St. Petersburg State Budgetary Healthcare Institution "Center of Family Planning and Reproductive Medicine". Histological and immunohistochemical (IHC) investigation of endometrial samples were conducted at the Anatomical Pathology Department of A.M. Nikiforov Federal Center of Emergency and Radiation Medicine, EMERCOM of Russia.

Histological examination of endometrium tissue fragments was carried out according to the standard protocol using Leica ASP200 tissue processor (Germany), by means of tissue staining with hematoxylin and eosin. The IHC study was performed via polymer method using the EnVision visualization system kit from "Dako Cytomation" (Denmark). We used monoclonal antibodies from "Dako Cytomation" (Denmark) to estrogen receptors $(E R)$ alpha (clone 1D5, RTU) and progesterone receptors (PR) (clone PgR 636, RTU). Evaluation of ER and PR expression in the glands and stroma of the endometrium was carried out by the Histochemical Score ( $\mathrm{H}$-score) method, based on computing the percentage of stained cell nuclei (up to 100\%) and staining intensity score (0 - no staining, 1 - weak, 2 - moderate, 3 - strong ) by the formula: $\mathrm{H}$ score $=1 \times(\%$ of cells with weakly stained nuclei $)+2 \times(\%$ of cells with moderately stained nuclei) $+3 \times(\%$ of cells with strongly stained nuclei); $\mathrm{H}$-score values were determined in the range $0-300$ (as modified by McCartey, 1986) [13].

On the day of the endometrial aspiration biopsy (day 6-8 after ovulation), venipuncture of the ulnar vein was performed to obtain a venous blood sample. Subsequently, it was tested at the Endocrine Laboratory of the Federal State Budgetary Institution "D.O. Ott Research Institute of Obstetrics, Gynecology and Reproductive Medicine" for the content of $E_{2}$ and $P$. Enzymelinked immunosorbent assays (ELISA) were used to determine blood levels of $E_{2}$ (test system by "DRG Diagnostics", Germany) and $P$ (test system by "Beckman Coulter", USA). Reference values for blood during the luteal phase of the menstrual cycle were 180$1070 \mathrm{pmol} / \mathrm{L}$ for $E_{2}$ and $16.1-59.1 \mathrm{nmol} / \mathrm{L}$ for $P$.

\section{Statistical analysis}

Statistical methods were used to process our results. The data were checked for normal distribution using Shapiro-Wilk test (nonnormal distribution of the studied values was determined). To identify the statistical significance of differences in experimental values, nonparametric statistical methods were employed. Descriptive statistics methods included of the median $(M e)$, along 
with lower and upper quartiles $(L Q, \cup Q)$ for studied parameters. Analysis of differences in values was performed using the MannWhitney U-test of nonparametric statistics. To study the statistical relationships between the indicators, nonparametric Spearman's rank correlation coefficients were used. Differences were considered statistically significant at $p<0.01$. The results were presented as percentages of the average and $95 \%$ confidence interval.

\section{Results}

The average body mass index (BMI) values in women of the main and control groups were within customary limits (BMI: 18.5$24.9 \mathrm{~kg} / \mathrm{m}^{2}$ ) (Table 1), 2 out of 33 patients in the main group were overweight (BMI: $29.4 \mathrm{~kg} / \mathrm{m}^{2}$ and $29.0 \mathrm{~kg} / \mathrm{m}^{2}$ ).

All women had a regular menstrual cycle. The characteristics of menstrual function in the main vs. control groups (age at menarche, duration of menstruation and duration of menstrual cycle) did not have significant differences $(p>0.01)$ and corresponded to the values in the population (Table 1 ). Dysmenorrhea was noted in $5(15 \%)$ women in the main group vs. $3(20 \%)$ in the control group, without significant difference $(p=0.9)$. In the last year prior to the inclusion into the study, some women with $\mathrm{MC}$ had a history of single episodes of menstrual dysfunction: $9(27 \%)$ of oligomenorrhea pattern and $4(12 \%)$ of polymenorrhea type. The ages at onset of sexual intercourse averaged $18(16,23)$ and $17(16,19)$ years old $(p>0.01)$ in main vs. control groups.

Among women with $M C$ in the main group $(n=33), 13$ patients (39\%), according to their obstetrics-and-gynecology anamnesis, had recurrent early pregnancy losses. Among these 13 women with recurrent early $M C$, in $77 \% \quad(n=10)$ cases, there was anamnestic data on the results of a cytogenetic study of abortion: no chromosomal pathology was found. In those situations when abortus karyotyping was performed, the karyotyping of the patients also took place earlier: all had a karyotype of $46 X X$. All women in the main group had a history of intrauterine interventions: $30 \%(n=10)$ had single uterus curettage, while $70 \%$ $(n=23)$ had two or more $[3(2,5)]$ intrauterine interventions.

According to ultrasound monitoring of folliculogenesis and ovulation, as well as $P$ level assessment in peripheral blood at day 6-8 after ovulation, it was determined that all women had an ovulatory menstrual cycle. The levels of sex hormones $\left(E_{2}\right.$ and $\left.P\right)$ in blood did not have significant differences in the studied women cohorts $(p>0.01)$ (Table 2$)$.

According to the results of a histological examination, a full secretory transformation of the endometrium corresponding to the day of the menstrual cycle was observed in all 15 fertile women of the control group. In the study group of women with $M C$, in $36 \%(n=12)$ cases, the endometrium had a full secretory transformation, with glands of the middle stage of the secretion phase; in $64 \%(n=21)$ cases, inferior secretory changes in the uterine mucosa were identified.

An IHC study of the endometrium in all healthy fertile women of the control group exhibited a synchronous decrease in $\mathrm{H}$-score of $E R$ in both glands and stroma in the endometrium during the middle stage of the secretion phase. The average $\mathrm{H}$-score of $E R$ were $80(60,90)$ and $80(60,110)$ in the glands and stroma, respectively. Moreover, $P R$ expression had the characteristics of an asynchronous response: weak expression in the glands in the presence of high expression in the stroma: $\mathrm{H}$-score of $P R$ in the glands was $40(0,50)$ and $P R$ in the stroma was $210(190,210)$. Such dynamics of quantitative indicators (H-scores) of $E R$ and $P R$ in the endometrium was observed at customary reference values of sex hormones in peripheral blood: $E_{2}=758(410,897) \mathrm{pmol} / \mathrm{L}, P=32$ $(27,68) \mathrm{nmol} / \mathrm{L}$ (the ratio of $E_{2} / P=16(14,27)$ (Table 2) and full secretory transformation of the endometrium, which corresponded to the variant of normal expression of hormone receptors during the ovulatory menstrual cycle [14].

Table 1. Age, BMI and characteristics of the menstrual function in women of main vs. control groups, Me (LQ, UQ)

\begin{tabular}{|c|c|c|c|}
\hline Indicators & Main Group (miscarriage) $(n=33)$ & Control Group $(n=15)$ & $p$ \\
\hline Age, yr & $31(27,34)$ & $26(24,32)$ & 0.800 \\
\hline $\mathrm{BMI}, \mathrm{kg} / \mathrm{m}^{2}$ & $20(19,23)$ & $22(19,23)$ & 0.922 \\
\hline Age at menarche, yr & $13(12,14)$ & $13(13,14)$ & 0.983 \\
\hline Duration of menstruation, $d$ & $5(4,7)$ & $5(5,7)$ & 0.996 \\
\hline Duration of menstrual cycle, $d$ & $30(30,32)$ & $31(30,33)$ & 0.965 \\
\hline
\end{tabular}

Table 2. E2 and P levels in blood, quantitative indicators of ER and PR counts in endometrium during ovulatory menstrual cycle in the patients with a history of miscarriage and in healthy fertile women, vs. morphological characteristics of endometrium, Me (LQ, UQ)

\begin{tabular}{lccc} 
Main Group (miscarriage) $(n=33)$ & Control Group $(n=15)$ \\
Indicators & Endometrium with inferior & Endometrium with full secretory & Endometrium with full \\
secretory transformation $(n=21)$ & transformation $(n=12)$ & secretory transformation \\
\hline
\end{tabular}
(1) (2) (3)

\begin{tabular}{|c|c|c|c|c|}
\hline & (1) & (2) & (3) & \\
\hline $\begin{array}{l}E_{2}, \mathrm{pmol} / \mathrm{L} \\
\text { (6-8 d after ovulation) }\end{array}$ & $703(493,961)$ & $788(382,890)$ & $758(410,897)$ & $\mathrm{p} 1-2=0.879, \mathrm{p} 1-3=0.566, \mathrm{p} 2-3=0.667$ \\
\hline $\begin{array}{l}P, \mathrm{nmol} / \mathrm{L} \\
\text { (6-8 d after ovulation) }\end{array}$ & $37(27,47)$ & $34(26,66)$ & $32(27,60)$ & $\mathrm{p} 1-2=0.798, \mathrm{p} 1-3=0.302, \mathrm{p} 2-3=0.364$ \\
\hline $\begin{array}{l}\text { M-echo, mm } \\
\text { (12-14 d.m.c.) }\end{array}$ & $7(6,8)$ & $7(6,9)$ & $8(6,9)$ & $\mathrm{p} 1-2=0.612, \mathrm{p} 1-3=0.586, \mathrm{p} 2-3=0.901$ \\
\hline $\begin{array}{l}E R \text { in the glands } \\
\text { (6-8 d after ovulation) }\end{array}$ & $240(160,280)$ & $100(70,150)$ & $80(60,90)$ & $\mathrm{p} 1-2=0.009, \mathrm{p} 1-3<0.001, \mathrm{p} 2-3=0.521$ \\
\hline $\begin{array}{l}E R \text { in the stroma } \\
\text { (6-8 d after ovulation) }\end{array}$ & $130(80,210)$ & $85(60,120)$ & $80(60,110)$ & $\mathrm{p} 1-2=0.697, \mathrm{p} 1-3=0.003, \mathrm{p} 2-3=0.097$ \\
\hline $\begin{array}{l}P R \text { in the glands } \\
\text { (6-8 d after ovulation) }\end{array}$ & $270(210,290)$ & $10(0,25)$ & $40(0,50)$ & $\mathrm{p} 1-2=0.000, \mathrm{p} 1-3<0.001, \mathrm{p} 2-3=0.431$ \\
\hline $\begin{array}{l}P R \text { in the stroma } \\
(6-8 \mathrm{~d} \text { after ovulation) }\end{array}$ & $270(240,280)$ & $275(260,285)$ & $210(190,210)$ & $\mathrm{p} 1-2=0.789, \mathrm{p} 1-3=0.012, \mathrm{p} 2-3=0.023$ \\
\hline
\end{tabular}


The normal expression variant of $E R$ and $P R$ was found in all $36 \%(n=12)$ of the main group patients with a history of MC and full secretory transformation of the endometrium without significant differences from the group of healthy fertile women. In the endometrium of remaining $64 \%(n=21)$ of main group women, a variant of $E R$ and $P R$ overexpression was discovered, which was characterized by high content of both types of receptors in the endometrial glands: $E R=240(160,280) ; P R=270 \quad(210,290)$, respectively, with significant differences in comparison with the control group $(p<0.01)$. The endometrial thickness values, according to ultrasound examination of pelvic organs ( $M$-echo) during the periovulatory period (12-14 d.m.c.) in women of the main and control groups were about $8 \mathrm{~mm}$ and did not differ significantly from each other ( $p>0.01)$ (Table 2).

The values of $E R$ and $P R$ levels in peripheral blood did not correlate with indicators of endometrial receptivity in the groups $(p>0.01)$.

\section{Discussion}

The specialized literature states that the most significant indicator of the hormone-receptor endometrial response is the expression of sex steroid receptors, especially $P R$, in endometrial glands. This expression undergoes a significant decrease on day 68 after ovulation, which reflects the full hormone-progesteronereceptor response of the uterine mucosa [15]. In the study by $S$. Petousis et al. (2016), it was shown that a normal ovulatory menstrual cycle was characterized by decrease in the expression of $P R$ in endometrial glands during the secretion phase [16]. I.A. Hramova et al. (2014) provided information on a sharp decrease in the expression of $E R$ in glandular and stromal cells of the endometrium and prolonged expression of $P R$ in the secretion phase [17]. We noted the characteristics (IHC method) of normal expression of endometrial receptors in the luteal phase of the ovarian cycle (middle phase of endometrial secretion): 1) a significant decrease in $P R$ and $E R$ expression in endometrial glands; 2) a declining trend of $E R$ expression in the stroma of the uterine mucosa. Moreover, in different cohorts of women, we observed $P R$ overexpression in endometrial stroma, which did not reflect the specificities of endometrial hormone-receptor response. Our data correlated with physiological impact of $P$ on the endometrium in the middle secretory phase of the endometrial cycle. The impact conveyed itself in decrease of the $E R$ and $P R$ expression in the glands, and did not contradict the data of other researchers [10, 18].

Overall, according to hormonal, ultrasound, and morphological evaluations of endometrial samples obtained on day 6-8 after ovulation, it was found that almost two-thirds of women with early $M C$ of unclear genesis during the ovulatory ovarian cycle had inferior secretory changes and overexpression of ER and PR in the endometrium. Among these patients, $90 \%(n=19)$ had two or more uterine curettes in their anamneses. It should be noted that, in women with inferior secretory transformation of the endometrium, in the absence of inflammatory infiltration, foci of uneven focal fibrosis were found in the stroma of the endometrium. Endometrial histoarchitectonics disorders can be observed as a result of exposure to various damaging factors (viral, bacterial, aseptic intrauterine invasive interventions, etc.) that trigger the process of true inflammation, or an inflammatory-like (possibly autoimmune) reaction and, as a result, proliferation of endometrial fibrous tissue [19]. All of these are accompanied by an imbalance of intercellular and molecular interactions, which can affect endometrial receptivity.

Ovulatory level of $P$ in peripheral blood is not a unique predictor providing a full phase secretory transformations of the endometrium.

In general, an analysis of the characteristics of $E R$ and $P R$ endometrial expression in women with uncertain causes of early pregnancy loss (strict exclusion criteria) in relation to the phase transformation of the endometrium and the values of the levels of sex steroids $\left(E_{2}\right.$ and $\left.P\right)$ in peripheral blood allowed obtaining data that most of these patients with a full ovulatory menstrual cycle had disorders of a hormonal-receptor interactions in their endometrium. Our results broadened the idea of endometrial dysfunction role (decreased receptivity of the endometrium) in the genesis of early $M C$ of unknown etiology. We did not encounter similar information for a cohort with comparable traits and similar conditions of indicator analysis in available scientific literature.

Hence, our results allowed clinicians conducting in-depth examination with combined (histological and $\mathrm{IHC}$ ) evaluation of endometrial samples in women with uncertain causes of early MC, despite the presence of a full ovulatory menstrual cycle. A special risk group was represented by women with a history of two or more uterine curettes.

A multicomponent analysis of the relationship between the values of $P$ level in blood and indicators of the morphological (histological and IHC) study of the endometrium in women with early $M C$ in the anamnesis revealed the signs of endometrial receptivity decrease and identified the group of patients who were suitable for progestogen therapy at the pregravid stage.

Our results may justify the feasibility of progestogen therapy at the pregravid stage in more than half of the women with a history of early MC, despite the presence of ovulatory menstrual cycle.

\section{Conclusion}

Nearly two-thirds of women (64\%) in the main group, with early miscarriage in anamnesis during the ovulatory phase of the menstrual cycle, exhibited signs of endometrial receptivity disorder, manifested by overexpression of estrogen and progesterone receptors and inferior secretory transformation of the endometrium. In $36 \%$ of the patients with an early pregnancy miscarriage, the endometrium corresponded to the middle phase of secretion with normal expression of hormone receptors, without significant differences from healthy fertile women.

Conflict of Interest: none declared.

\section{References}

1. Recurrent pregnancy loss. ESHRE Early Pregnancy Guideline Development Group. Guideline of the European Society of Human Reproduction and Embryology, 2017; 154 p. https://www.eshre.eu/Guidelines-and-Legal/Guidelines/Recurrentpregnancy-loss.

2. Huang J, Jin N, Qin H, Shi X, Liu Y, Cheung W, et al. Transcriptomic profiles in peripheral blood between women with unexplained recurrent implantation failure and recurrent miscarriage and the correlation with endometrium: A pilot study. PLoS One 2017; 12(12): e0189159. https://doi.org/10.1371/journal.pone.0189159. 
3. Zegers-Hochschild F, Adamson GD, de Mouzon J, Ishihara O, Mansour $\mathrm{R}$, Nygren $\mathrm{K}$, et al. The International Committee for Monitoring Assisted Reproductive Technology (ICMART) and the World Health Organization (WHO) Revised Glossary on ART Terminology, 2009. Hum $\begin{array}{lll}\text { Reprod 2009; 26(11): } & \text { 2683-2687 }\end{array}$ https://doi.org/10.1093/humrep/dep343.

4. Haouzi D, Bissonnette L, Gala A, Assou S, Entezami F, Perrochia H, et al. Endometrial receptivity profile in patients with premature progesterone elevation on the day of HCG administration. Biomed Res Int 2014; 2014: 951937. https://doi.org/10.1155/2014/951937.

5. Krylova YuS, Kvetnoy IM, Aylamazyan EK. Endometrial receptivity: the molecular mechanisms regulation of implantation. Journal of obstetrics and women's diseases 2013; 62(2): 63-74. Russian. https://elibrary.ru/item.asp?id=20144389.

6. Pluchino N, Drakopoulos P, Wenger JM, Luisi S, Russo M, Genazzani AR, et al. Endocrinology of pregnancy loss. In: Reccurent pregnancy loss. Causes, controversies and treatment. Carp HJA, ed. 2nd ed. CRC Press, 2015: 111122. http://gynecology.sbmu.ac.ir/uploads/1 4965273251224748083.pdf.

7. Casper RF. It's time to pay attention to the endometrium. Fertil Steril 2011; 96(3): 519-521 https://doi.org/10.1016/j.fertnstert.2011.07.1096.

8. Krasnopolsky VI, Logutova LS, Zarochentseva NV, Dub NV, Tishchenko YuP, Ovchinnikova VV, et al. Pregravid preparation of women with miscarriage and chronic endometritis. Moscow, 2014; 31 p. Russian. http://allokin.ru/netcat files/154/190/1.Pregravidarnaya_podgotovka. pdf.

9. Liang $Y X$, Liu L, Jin ZY, Liang $X H, F u ~ Y S, ~ G u ~ X W$, et al. The high concentration of progesterone is harmful for endometrial receptivity and decidualization. Sci Rep 2018; 8(1): 712. https://doi.org/10.1038/s41598-017-18643-w.

10. Aylamazyan EK, Tolibova GH, Tral TG, Kogan IU, Yarmolinskaya MI, Tsipurdeeva AA, et al. New approaches to the estimation of endometrial dysfunction. Journal of obstetrics and women's diseases 2017; 66(3): 8-15. Russian. https://doi.org/10.17816/JOWD6638-15. .

11. Ruiz-Alonso $M$, Blesa $D$, Díaz-Gimeno $P$, Gómez $E$, Fernández-Sánchez $\mathrm{M}$, Carranza $\mathrm{F}$, et al. The endometrial receptivity array for diagnosis and personalized embryo transfer as a treatment for patients with repeated implantation failure. Fertil Steril 2013; 100(3): 818-824. https://doi.org/10.1016/j.fertnstert.2013.05.004

12. Huang J, Jin N, Qin H, Shi X, Liu Y, Cheung W, et al. Transcriptomic profiles in peripheral blood between women with unexplained recurrent mplantation failure and recurrent miscarriage and the correlation with endometrium: A pilot study. PLoS One 2017. 12(12): e0189159. https://doi.org/10.1371/journal.pone.0189159.

13. Ellinidi VN, Anikeyeva NV, Maksimova NA. Practical immuno(cyto)histochemistry (Guidelines). St. Petersburg: Federal Center for Emergency and Radiation Medicine at the Russian Federation Ministry of Emergency Situations, 2002; 36 p. Russian.

14. Aganezov SS, Ellinidi VN, Ponomarenko KYu, Morotskaya AV, Aganezova NV. Features of the hormone-receptor interaction in the endometrium during ovulatory menstrual cycle in women with reproductive failure. Bulletin of the Russian Military Medical Academy 2018; (2(62)): 63-67. Russian. https://elibrary.ru/item.asp?id=35185352.

15. Ponomarenko KYu. Endometrial receptivity in women with disorders of reproductive system. Journal of obstetrics and women's diseases 2017; 66(4): 90-97. Russian. https://doi.org/10.17816/JOWD66490-97.

16. Petousis S, Prapas Y, Margioula-Siarkou C, Milias S, Ravanos K, Kalogiannidis I, et al. Expression of progesterone receptors is significantly impaired in the endometrium of infertile women during the implantation window: a prospective observational study. J Matern Fetal Neonatal Med 2016; 29(23): 3912-3919 https://doi.org/10.3109/14767058.2016.1152244.

17. Khramova IA, Slusareva EE, Karedina VS. Secretory-synthetic kinesis of monocytes/macrophages and receptor-expressing to the reproductive hormones in the endometrium. Fundamental research 2014; (4-1): 181-185. Russian https://elibrary.ru/item.asp?id=21309258.
18. Patel B, Elguero S, Thakore S, Dahoud W, Bedaiwy M, Mesiano S. Role of nuclear progesterone receptor isoforms in uterine pathophysiology. Hum Reprod Update 2015; 21(2): 155-173 https://doi.org/10.1093/humupd/dmu056.

19. Radzinskiy VE, Kiselev VI, Muyzhnek EL, Ordiyants IM, Dobretsova TA. Chronic endometritis and fertility: new answers. Therapeutic options for overcoming chronic inflammation in the endometrium and improving fertility: fact sheet. Moscow: StatusPraesens, 2016: $24 \mathrm{p}$ Russian. https://old.praesens.ru/khronicheskiy-endometrit-i-fertilnostnovye-otvety

\section{Authors:}

Sergey S. Aganezov - PhD, Associate Professor, Department of Obstetrics and Gynecology, North-Western State Medical University n.a. I.I. Mechnikov, St. Petersburg, Russia. http://orcid.org/0000-0002-3523-9922. Vera N. Ellinidi - PhD, Associate Professor, Head of the Department of Pathology, Federal Center of Emergency and Radiation Medicine n.a. A.M. Nikiforov, Moscow, Russia. http://orcid.org/0000-0002-7091-3142.

Kristina Yu. Ponomarenko - Postgraduate Student, Department of Obstetrics and Gynecology, North-Western State Medical University n.a. I.I. Mechnikov, St. Petersburg, Russia. http://orcid.org/0000-0002-3060-7116. Anastasiya V. Morotskaya - Postgraduate Student, Department of Obstetrics and Gynecology, North-Western State Medical University n.a. I.I. Mechnikov, St. Petersburg, Russia. http://orcid.org/0000-0001-6783-1923. Natalia V. Aganezova - MD, PhD, Professor, Associate Professor, Department of Obstetrics and Gynecology, North-Western State Medical University n.a. I.I. Mechnikov, St. Petersburg, Russia. http://orcid.org/00000002-9676-1570. 